This is an electronic reprint of the original article. This reprint may differ from the original in pagination and typographic detail.

Author(s): Yrjönsuuri, Mikko

Title: Obligations and conditionals

Year: $\quad 2015$

Version:

Please cite the original version:

Yrjönsuuri, M. (2015). Obligations and conditionals. Vivarium, 53(2-4), 322-335.

https://doi.org/10.1163/15685349-12341302

All material supplied via JYX is protected by copyright and other intellectual property rights, and duplication or sale of all or part of any of the repository collections is not permitted, except that material may be duplicated by you for your research use or educational purposes in electronic or print form. You must obtain permission for any other use. Electronic or print copies may not be offered, whether for sale or otherwise to anyone who is not an authorised user. 


\title{
Obligations and Conditionals
}

\begin{abstract}
The paper considers two kinds of medieval obligational disputations (positio, rei veritas) and the medieval genre of sophismata in relation to the kinds of inferences accepted in them. The main texts discussed are the anonymous Obligationes parisienses from the early thirteenth century and Richard Kilvington's Sophismata from the early fourteenth century. Four different kinds of warranted transition from an antecedent to a consequent become apparent in the medieval discussions: (1) the strong logical validity of basic propositional logic, (2) analytic validity based on conceptual containment, (3) merely semantic impossibility of the antecedent being true without the consequent, and (4) intuitively true counterfactual conditionals. As these different kinds of consequences are spelled out by means of obligational disputations, it appears that the genre of obligations is indeed useful for the "knowledge of consequences" as the anonymous Obligationes parisienses claims.
\end{abstract}

KEYWORDS

Obligationes, sophismata, conditionals, consequences, counterfactuals, validity.

The medieval obligations logic concerned the duties of a respondent in a disputation that starts with some special obligation given to the respondent. Most typically, this special obligation binds the respondent to grant to the opponent a specified false sentence whenever the opponent puts it forward. This species of obligation was called positio and the specified sentence was called the positum. As the special obligation did not completely relieve the respondent from the general prima facie duties of logical coherence and of truthfulness, rules were given concerning how the respondent ought to act in such a disputation. The basic aim of the rules was usually to guide the respondent so that he can avoid granting and denying the same sentence, which was in the circumstances understood as granting further falsities in addition to what was specified in the obligation itself.

In this paper I will consider, in addition to positio, also another species of obligations, rei veritas. This species too concerns laying down a false sentence to be accepted in the disputation, but in a way different from how the positum is accepted. Also, I will relate the treatment of casus in the sophism 47 of Richard Kilvington's Sophismata to these two species of obligtions. My particular 
problem in this paper is to understand how the three techniques can be and were used in analysing inferential relations between sentences.

\section{Consequences in Obligationes Parisienses}

The anonymous early thirteenth century treatise Obligationes parisienses claims that the study of inferential relations is the purpose of obligational disputations. The introduction of this text describes how an obligational disputation is useful in the acquisition of "knowledge of consequences" (scientia de consequentiis). The author thinks that when a special obligation is given and accepted, the disputation does not concern what is true or believed as such, but only in relation to the given obligation. Thus, anything that follows from the given obligation needs to be taken into account. Thus, if the respondent is given the duty to grant a specified sentence, he must also grant anything that follows logically from it in order to avoid contradicting himself. ${ }^{1}$

In general, the idea is understandable. Without any special obligation, the respondent can remain coherent simply by following the truth and granting only what is true. But when a false sentence is given as the starting point, logical coherence can be achieved only by careful observance of the logical relations between the sentences put forward in the disputation. Turning this general idea into actual practice is however rather complex as can be noticed through actually engaging in an obligational disputation. Rules for the respondent are indeed needed to make the task easier when the number of sentences to be evaluated increases and their inferential relations get more complex. Furthermore, as the author of Obligationes parisienses notes, one may need to recognize different kinds of inferential relations.

In an interesting passage, the introduction of Obligationes parisienses points out that one needs to be aware how contingent (casualis) sentences differ from those expressing necessary subject matter. ${ }^{2}$ The examples introduced by the author are illuminative. First, consider the following two sentences:

1. Socrates is an animal

2. Socrates is a man

Here 2. follows from 1. through Socrates's essence: if he exists, he is necessarily a man, and if he is an animal, he does exist. However, the inference from 1 . to 2 . is not a natural consequence (consequentia naturalis) according to the terminology used by the author. He seems to mean that no matter how necessary the inferential relation is it is not grounded in anything like conceptual inclusion of the consequent in the antecedent, as the standard requirement for natural consequences was at the time often formulated. It is valid, however, since 1. cannot be true without 2 . also being true. The accidental character of the

\footnotetext{
${ }^{1}$ An edition of the treatise is in L. M. De Rijk, 'Some Thirteenth Century Tracts on the Game of Obligation II', Vivarium 13 (1975), 22-54; see p. 27.

2 'And thus this genus of disputation is more used in contingent matters, since in them a consequence is more manifest than in necessary matters.' De Rijk, 'Some Thirteenth Century Tracts II', 27.
} 
consequence can, as the author points out, easily be seen by comparison to the following pair of sentences:

3. Socrates is coloured.

4. Socrates is white.

Here 4. does not follow from 3., since there is no such logical connection nor does Socrates's essence imply anything about his particular colour.

A similar situation concerning validity can be found in the following disputation example, which the author of Obligationes parisienses discusses. ${ }^{3}$ The example illustrates how inferential reasoning processes take place in obligational disputations. The idea is not just to take two sentences and to consider whether there is an inferential relationship between them, but rather to develop a more complex inferential structure. The following table gives as an ordered sequence the positum, the propositions put forward by the opponent, and the respective answers of the respondent with their appropriate explanations.

D1

Pos: Antichrist exists.

Pr1: Antichrist is coloured.

Pr2: Antichrist is white.

Pr3: Antichrist is not of a middle colour.

Pr4: Antichrist is black.
Accepted as possible.

Granted as sequent.

Denied as false non sequent.

Granted as true non repugnant.

Granted as sequent.

The advice given by the author is that at each step the respondent should proceed so that he first notes the actual truth value of the sentence put forward. If the sentence is false, he should consider a conditional sentence where the antecedent is a conjunction consisting of the positum together with all the granted sentences and the opposites of the denied sentences, and the consequent is the evaluated sentence. The point in considering the conditional is in finding out whether its consequent is sequentially relevant, or 'follows' in the disputation. Thus, the author thinks that conditionals are taken to express consequences.

If the respondent follows this advice in disputation D1, on the first step he first notes that Pr1 is false. Since nothing else has yet been put forward, the conditional to be considered is simple:

$$
\text { Con1: Pos --> Pr1 }
$$

As the author notes, this conditional is true (If Anticrist exists, Antichrist is coloured). Perhaps interestingly, the conditional can be compared to the pair of sentences 1 . and 2. above, and thus the consequence expressed by this conditional would not be a natural one (naturalis). No doubts about its validity

${ }^{3}$ De Rijk, 'Some Thirteenth Century Tracts II', 29-30. 
or acceptability ${ }^{4}$ are nevertheless mentioned in the Obligationes parisienses text, which merely points out that the conditional is true. Therefore, Pr1 is sequent and needs to be granted despite its falsity.

On the next step, Pr2 is evaluated in similar manner. It is first noted that it is false. Then, the respondent should consider the specified conditional. Its antecedent is a conjunction of the positum and the first proposition Pr1, which has been granted.

\section{Con2: Pos \& Pr1 --> Pr2}

Now, this conditional is false, since it does not follow from Antichrist existing and being coloured that he is white. The respondent should therefore note that the proposition Pr2 is false, and does not follow from earlier granted propositions. Thus, it should be denied.

Further, when the respondent has to evaluate a proposition that he notes to be true, it has to be checked whether it is repugnant. This means that in the case of Pr3 the respondent should consider the following conditional:

\section{Con3: Pos \& Pr1 \& -Pr2 --> -Pr3}

As the author notes, this conditional is false and the negation of Pr3 does not follow, which means that Pr3 itself is not to be evaluated as repugnant. As it is true, it is then granted.

The conditional becomes increasingly complex when the disputation continues. When evaluating Pr4, the respondent notes its falsity and checks whether it follows through considering the conditional:

$$
\text { Con4: Pos \& Pr1 \& -Pr2 \& Pr3 --> Pr4 }
$$

Since this conditional expresses a valid inferential relation and is thus true, $\operatorname{Pr} 4$ must be granted despite its falsity.

This detailed description of what the respondent of an obligational disputation actually does makes clear the role of conditionals in the evaluation of the propositions. It remains however an open question what kinds of conditionals are considered true in this context. As already noted, the author does not require that a conditional is true only if it expresses a natural (naturalis) consequence. It is also evident that the anonymous author does not have in mind what is nowadays called a material implication. For the truth of the kind of conditional

\footnotetext{
${ }^{4}$ An interestingly different case is the species of obligations called positio impossibilis. There only natural or direct (recta) consequences are acceptable. See eg. L.M. De Rijk, 'Some Thirteenth Century Tracts on the Game of Obligation I', Vivarium 12 (1974), 94-103; see pp. 118-119; translation in Anonymous, 'The Emmeran Treatise on Impossible Positio', in Medieval Formal Logic, ed. M. Yrjönsuuri (Dordrecht - Boston - London, 2001), 217-223: see p. 218-219.
} 
that the author has in mind it is required that there is some kind of necessary relation between the antecedent and a consequent.

Any reader with a twentieth century education in philosophy must at this point keep in mind that in the early thirteenth century there were no unanimously accepted general criteria for validity of an inference apart from the semantic criterion that the antecedent cannot be true without the consequent. In particular, logicians were not educated with a concept of formal validity based on substitutability of the material parts of the relevant sentences in the sense in which we nowadays know such a concept. Something like it may have been applicable to syllogistic logic, but logicians were from the context of the treatises of syncategorematic terms well aware of the fact that there are non-syllogistic valid inferences. Indeed, the above-mentioned examples from the Obligationes parisienses are non-syllogistic.

It seems that the obligational context proved useful in helping to distinguish different types of inferential validity. The conditional Con1 is not related to a formally valid inference in the sense in which we nowadays speak of formal validity. It is valid because of the nature of Antichrist: his nature differs from eg. angelic nature so that if he exists, he must exist as a material object that has a colour. Furthermore, the disputation accepts also that the conditionals can rely on a three-part division of colours into white, black and the middle. This division appears to work in the example as a logical fact, a fact on which logical inferences can be grounded. If this fact could not be taken into account, the conditional Con 4 would fail to be true. It is however, central to the argumentation and thus the anonymous author clearly thought it to be acceptable in this context. The inferential considerations behind the truth evaluations of all the conditionals are obviously non-syllogistic and reflect no apparent formality based on substitutivity.

Given the authors remark in the introduction that the inference from 1. to 2 . is not natural one, he seems to distinguish these inferences from direct conceptual containment. The inference from 2. to 1 . would reflect the conceptual containment of 'animal' in 'man' that can be made explicit by the definition of man as a rational animal. The anonymous author could perhaps accept that as a 'natural' consequence. But the conditionals considered in D1 are not of this kind.

It is clear, on the other hand, that the anonymous author did not think that these conditionals would be counterfactual conditionals in the sense in which 20th century logicians discussed counterfactuals. First, if we apply our contemporary classifications of conditionals, these are to be understood in indicative mood. Furthermore, their truth seems to be taken to be logical. In order to see in what sense their truth is logical, we however need to consider more complexities in the obligational structure, and in particular the species of obligations called 'rei veritas'.

When distinguishing between the different kinds of obligations, the anonymous author points out that in the kind of obligation called 'rei veritas' answers differ from those given in positio. That is, if the respondent is obligated to the sentence 
'Antichrist exists' in the species rei veritas, he should answer with doubt to the sentence 'Antichrist is white'. 5 The author's point seems to be applicable to the respondent in the disputation example D1. He denies Pr2 in D1. If he was instead in a disputation proceeding with a rei veritas, he should answer with doubt at Pr2. That is, the disputation would proceed as follows:

D2

RV: Antichrist exists. Pr1: Antichrist is coloured.

Accepted as possible.

Pr2: Antichrist is white. Granted as sequent. Doubted.

It seems that the author thought that in rei veritas the answers should be given on the basis of reasoning that has to some extent the same mode of thought that we find in the 20th century understanding of counterfactual conditionals. If Antichrist existed, he would be of some colour, but the respondent does not know which. It is noteworthy that in D1 (based on a positum) the answers to Pr2 and Pr3 (which are judged non sequent and non repugnant) are given in accordance with their actual truth-value and not in relation to a situation where 'Antichrist exists' is true. Assigning a colour to Antichrist is false because actually Antichrist does not exist and thus has no colour either. But in D2 where the obligation is in the species rei veritas, answers reflect the situation where the given sentence is true: this appears to be reminiscent of counterfactual reasoning. Unfortunately Obligationes parisienses does not contain a proper discussion of rei veritas. From other treatises we do find somewhat more substantial discussions, which indeed point to the direction that it was understood as the kind of obligational disputation that leans on counterfactual reasoning. The respondent is often required to answer as if he knew the rei veritas to be true. ${ }^{6}$

As a further complexity, Obligationes Parisienses as well as other obligations treatises discuss disputation examples involving a double structure of both rei veritas and positum. First some contingent sentence is given as the rei veritas and then something else, often its opposite is given as a positum. Consider the following disputation: ${ }^{7}$

D3

RV: Socrates is black. Accepted as possible.

Pos: Socrates is white. Accepted as possible.

Pr1: Socrates is white and you are not a bishop.

Denied as false non sequent.

Pr2: Socrates is white. Granted as sequent.

Pr3: You are a bishop. Granted as sequent.

Here rei veritas is used to ascertain the falsity of the positum, and more exactly the falsity of the first conjunct of Pr1. If Socrates was white as the positum claims,

5 De Rijk, 'Some Thirteenth Century Tracts II', 28.

${ }^{6}$ See Sara Uckelman, 'Sit verum and Counterfactual Reasoning', forthcoming.

7 De Rijk, 'Some Thirteenth Century Tracts II', 31. 
the conjunction would be true (given that the respondent is a student in logic and not a bishop), but the possible truth of the positum is not at issue in the disputation. The role of the positum is not to serve as a basis of counterfactual reasoning, but as a false premise in logical reasoning. Positum is used in inferential determination of correct answers, but the truth values considered in the answers are decided on the basis of the rei veritas. The disputation D3 is given by the author as an unproblematic illustration of his rule that on the basis of a false positum it is possible to prove any contingent proposition in the disputation. The rule as such also attests to the idea that positum is not developed counterfactually but as a starting point of logical inferences. Thus, the point is exactly that Pr3 is a false sentence completely unrelated both to the rei veritas and to the positum before the inferential structure is built. Still it has to be granted in the disputation.

The double structure of the rei veritas and the positum seems to be in place in order to make explicit the separation of truth and logic in obligational disputations. While rei veritas provides the ground for truth-value evaluations, positum is used in logical inferences. This structure emphasizes the detachment of the positum from genuine truth-value considerations. The positum is not to be taken as true, but as a starting point of inferences in the disputation.

\section{Obligations and the Casus in Sophismata}

Thirteenth century obligations treatises often use the word "casus" at the place where the author of Obligationes Parisienses used in the above example the expression "in veritate" associated with the species of obligations called rei veritas. The term casus associates the technique with practices used in the context of what was then called sophisms (sophismata). In a sophism, there is a casus given, and on the basis of the casus arguments are constructed for and against some specific sentence called the sophism itself. As the thirteenth century treatments of sophisms often use also other technicalities of obligational disputations, we may ask whether the casus in a sophism ought to be understood as a kind of obligation, and perhaps more exactly an obligation in the species rei veritas?

This would be a straightforward question to ask from any medieval logician who knew both genres. Unfortunately nothing seems to be said about the matter in the thirteenth century texts known to modern scholars. But in the early fourteenth century Richard Kilvington seems to tackle the issue. In sophism 47 of his Sophismata, ${ }^{8}$ he turns into discussion of the rules of obligations, apparently because he thinks that in a sophism one should obey the rules of obligations. Kilvington's discussion has been considered by many scholars writing on

${ }^{8}$ Edition in Richard Kilvington, The Sophismata of Richard Kilvington, eds. Norman Kretzmann and Barbara Ensign Kretzmann (Oxford, 1990); translation in Richard Kilvington, The Sophismata of Richard Kilvington, introduction, translation and commentary by Norman Kretzmann and Barbara Ensign Kretzmann (Cambridge, 1990). 
obligations, ${ }^{9}$ and I will not go into all of its details here. For our purposes the main point is that he seems to be claiming that the standard rules for positio will not work in the sophism that he is discussing. If they are obeyed, the sophism cannot be solved. Instead, he puts forward a revision of the rules. It seems that his thinking is similar to what thirteenth century thinkers had in connection to rei veritas. It is noteworthy though that Kilvington clearly aims at devising suitable rules, while no thirteenth century author is known to have even tried to give rules for answering in a rei veritas disputation. For example, the above considered anonymous author of Obligationes parisienses simply refrains from giving any rules.

The core of the revision to the obligational rules Kilvington suggests is that the respondent ought to grant what would be true if the positum were true. As he recognizes, this principle requires that the respondent ought to grant anything that follows logically. In this respect, his rules are similar to what we find in the earlier authors. But there is more. He suggests that a sentence like Pr1 in D3 above is affected by the positum and ought not be denied but instead granted. Kilvington's point is that if you assume that Socrates is white, the conjunction 'Socrates is white and you are not a bishop' ought to be evaluated as consisting of a sentence assumed to be true and an independent truth. A conjunction of truths should then be evaluated as true and thus it ought to be granted in the disputation. This reasoning seems characteristically counterfactual in a sense related to the twentieth century discussion.

The actual sophism Kilvington discussed has the casus "if the king is seated, you know that the king is seated, and if the king is not seated, you know that he is not seated" (let us call this K). The casus thus tells that whether the king is seated or not, you will know it. As I read Kilvington's text, he is thinking that obligational rules ought to help in evaluating the sophisma sentence "You know that the king is seated". Let us therefore construct the sophism as an obligational disputation with the casus as a starting point.

As is clear to any logician, the casus implies nothing about whether the king is seated and thus does not decide which one of the contradictory pair you know, but it does imply that you know one of them. This logical structure can be used in an obligational disputation in many ways. Consider first the following example following the standard rules for positio:

D4

Pos: $\mathrm{K} \quad$ Accepted as possible.

Pr1: You know that the king is not seated.

Denied as false non sequent.

Pr2: You know that the king is seated Granted as sequent

\footnotetext{
${ }^{9}$ See esp. Angel d'Ors, 'Tu scis regem sedere (Kilvington, S47[48])', Anuario filosófico 24 (1991), 66-67; and Stephen Read, 'Richard Kilvington and the Theory of Obligations', forthcoming.
} 
Kilvington does not accept these answers. He takes it to be problematic that inverting the order of Pr1 and Pr2 for another disputation would yield the opposite answers. If Pr2 was put forward first, it would have to be denied, and after it Pr1 granted. According to the rules given by the author of Obligationes parisienses (and eg. Walter Burley) this would be correct and unproblematic.

But consider the following disputation in the species of rei veritas following the suggestion made by the author of Obligationes parisienses discussed above in connection to disputation D2.

D5

RV: K

Pr1: You know that the king is not seated.

Accepted as possible.

Doubted.

Pr2: You know that the king is seated Doubted.

The respondent has to answer with doubt because he cannot judge which one of the two he would know. This is the way Kilvington thinks that the sophism ought to be treated. It seems that he requires that in sophisms the casus should be treated in the way that 13th century authors treated rei veritas and not in the way positum was treated. From this viewpoint he may be described as trying by his revision to give rules of rei veritas, which earlier authors had opted not to attempt.

We need to attend to one more sentence in Kilvington's discussion. He formulates a clear counterfactual conditional in order to prove his point: ${ }^{10}$

$\mathrm{CF}$

For if you were in Rome and you were not a bishop, this would have to be denied: 'You are in Rome' and 'you are a bishop' are alike [in truth value].

The sentence comes in connection to an obligational disputation that could proceed as follows:

D6

Pos: You are in Rome. Accepted as possible.

Pr1: You are a bishop. Denied as false non sequent.

Pr2: 'You are in Rome' and 'you are a bishop' are alike.

Denied as repugnant.

Kilvington's counterfactual conditional cited above (CF) is similar to the conditional suggested by the author of Obligationes parisienses as a help for the respondent in evaluating Pr2. It has otherwise the same antecedent, but formulated in the subjunctive mood whereas the Obligationes parisienses recommends indicative mood. In the consequent, there is a slight difference. In $\mathrm{CF}$, Kilvington does not have Pr2 directly as the consequent, but jumps to the

10 Kilvington, Sophismata, S47, (cc). 
practical conclusion concerning its evaluation. This difference I take to be insignificant here.

D6 follows the standard rules of obligations. However, the example that Kilvington actually discusses does not have Pr1 as a proposition explicitly put forward but jumps directly to what is Pr2 in the table. Without the respondent first denying that he is a bishop, Pr2 would according to the standard rules be evaluated as true and irrelevant, because it is actually true and its opposite does not follow from the positum alone (conditional Pos --> -Pr2 is false). Kilvington wants however the respondent to consider the situation as it would obtain if the positum was true, and to give his answers in accordance to that situation. $\mathrm{He}$ does not ask the respondent to evaluate conditionals of the type introduced by the author of Obligationes parisienses, but he wants the respondent to answer as he would if the situation was as described by the positum together with some actual facts, as here the fact that the respondent is not a bishop.

Kilvington does not have any rules concerning which facts can be taken into account. He seems to be rather safe in assuming that being in Rome would not make the respondent a bishop, or (following David Lewis's understanding of counterfactuals) ${ }^{11}$ that the world where the respondent is still a young logic student despite going to Rome is more similar to the actual world than if he were in Rome as a bishop. However, as twentieth century logicians have noticed, introducing additional premises in counterfactual reasoning is not always as innocent as it is in this example. Kilvington does not have anything to say about this problem, or how the reasoning should proceed apart from the general idea that the respondent ought to think of what he would grant if he were in the situation.

This general idea does however provide Kilvington a solution to the sophism he is discussing. If the respondent considers what he would grant if he were in the situation described by the casus, he has to refrain from denying that he knows the king to be seated or that he knows that the king is not seated. However, neither of these follows from the casus, and thus there also is no reason to grant either one of them. If the casus were true, the respondent would know one of the alternatives to be true, but he does not actually know which one, and thus he has to doubt both in the actual disputation. As William Heytesbury was later to point out, $^{12}$ this has the unhappy consequence that the respondent must doubt whether he knows in a situation where knowing would seem to imply knowing that one knows. Kilvington's solution is thus not fully satisfactory.

Here our interest however is simply the distinction between the two approaches adopted by the author of Obligationes Parisienses in his treatment of positio and by Kilvington in his Sophismata, sophism 47 . The anonymous author invites the

11 David Lewis, Counterfactuals (Oxford, 1973).

12 William of Heytesbury, 'The Verbs 'Know' and 'Doubt', translated Norman Kretzmann and Eleonore Stump, in The Cambridge Translations of Medieval Philosophical Texts, Vol. 1: Logic and Philosophy of Language (Cambridge, 1988), 436-439. 
respondent to look at the actual sentences and the concepts used in them - and to ignore the how the situation would be if the positum was true. Instead of this, Kilvington would have the respondent to consider the situation and to answer on that basis - without much recognition of the logical relations between sentences.

\section{Conclusion}

The central difference between the theories of obligations in Obligationes parisienses and Kilvington's Sophismata, sophism 47, is that Kilvington relies to counterfactual reasoning and has considerations based on the truth of counterfactual conditionals. The conditionals that Obligationes parisienses discusses are best described as expressing relations of logical validity. It is however noteworthy that Obligationes parisienses recognizes that the validity at issue need not be of the kind that he calls 'natural'.

Given that the considered obligational disputations also rely on principles of basic propositional logic, we must distinguish altogether four kinds of inferential relationships. First, inferential connections that we nowadays would not hesitate to call formally valid inferences in basic propositional logic. For example, from denial of a part of a conjunction, denial of the conjunction follows. Second, natural consequences (consequential naturalis) where the inferential connection is based on conceptual containment of the consequent in the antecedent. These a modern logician might call analytic perhaps in distinction from being formally valid. For example, 'if Socrates is a man, he is an animal'. Third, consequences which do not fill either of these two strong criteria of validity but fill the modal criterion of it being impossible for the antecedent to be true without the consequent. For example, 'if Socrates is an animal, he is a man'. And fourth, the weaker inferential relationship that was in the twentieth century labelled counterfactual reasoning. Here the modal criterion of validity is not filled, but still there is some warrant for moving from the antecedent to the consequent.

It seems thus that the anonymous author of Obligationes parisienses is right in connecting the art of obligations to the 'knowledge of consequences' (scientia de consequentiis). This art is indeed a useful tool in bringing forward considerations of various kinds of inferential relationships. Given that the thirteenth and early fourteenth centuries were a period in which logic saw very much development, and given that the conceptions of what it means that there is an inferential connection between a set of premises and a conclusion, it seems not to be far fetched to suppose that the technique of obligational disputations played an important role in these developments. Insofar as this is the case, it is very important to bear in mind that the discussion concerning obligations concentrated on intra-linguistic or syntactic relations between sentences. While medieval logicians did think that an inference is valid only if premises cannot be true without the conclusions, authors writing on obligations were interested in inferential relations whose validity could be seen from conceptual or syntactic relations between sentences. This seems to suggest that most authors thought that obligational disputations in the standard species of positio ought not be understood from the viewpoint of models. The idea that the assumed proposition picks out a model in which all subsequent answers are true may have been at issue in rei veritas, and the reason why Kilvington wanted to revise 
the rules for the purposes of sophisms. What is more at stake in a standard positio, is the relation between proof-theoretically interpretated consequences and alethic modalities. The core philosophical question is, thus, to spell out how and when exactly a sentence is repugnant to another so that they cannot both be true. ${ }^{13}$

${ }^{13}$ For further discussions of how validity was understood in late medieval logic, see eg. Catarina Dutilh-Novaes, 'Form and Matter in Later Latin Medieval Logic: The cases of suppositio and consequentia', Journal of the History of Philosophy 50 (2012), 339-364; Calvin Normore, 'The necessity in deduction: Cartesian inference and its medieval background', Synthese 96 (1993), 437-454; Stephen Read, 'Inference', in The Cambridge History of Medieval Philosophy, ed. R. Pasnau (Cambridge, 2010), 173-185. For twentieth century theories, see e.g. J.

Etchemendy, The Concept of Logical Consequence (Harvard, 1990). 